\title{
YLD 2000 akma fonksiyonu parametrelerinin belirlenmesinde ardışık kuadratik programlama ve aktif set metotlarının performanslarının incelenmesi
}

\section{Investigation of performances of sequential quadratic programming and active- set methods in the determination of YLD2000 yield function parameters}

\author{
Bora Şener ${ }^{1, *}$ (it) \\ ${ }^{l}$ Ylldız Teknik Üniversitesi, Makine Mühendisliği Bölümü, 34349, İstanbul Türkiye
}

\begin{abstract}
Özet
Bu çalışmada, Yld2000 akma fonksiyonunun katsayılarının belirlenmesinde nümerik optimizasyon tekniklerinden ardışık kuadratik programlama ve aktif-set metotlarının performansları değerlendirilmiştir. Çalışmada iki alüminyum alaşımı (AA6111-T4, AA6181-T4) ve bir yüksek mukavemetli sac malzeme (DP980) seçilmiştir. Yöntemler, hata fonksiyonunu yakınsama hızlarına ve minimizasyon sirasında inceledikleri fonksiyon sayısına göre değerlendirilmiş olup, üç malzeme için de aktif-set metodunun ardışık kuadratik programlamaya göre daha başarılı olduğu belirlenmiştir. Metodu doğrulamak için, belirlenmiş katsayılara göre malzemelerin akma gerilmesi oranları, Lankford katsayılarının sac düzlemi içerisindeki değişimleri ve akma yüzeylerinin pozitif bölgeleri tahmin edilmiş ve teorik sonuçlar deneysel sonuçlarla karşılaştırılmıştır. Yapılan karşılaştırmalardan malzemelerin düzlemsel anizotropilerinin ve pozitif bölgede akma yüzeylerinin başarılı bir şekilde tahmin edilebildiği görülmüştür.
\end{abstract}

Anahtar kelimeler: Yld2000, Ardıșık kuadratik programlama, Aktif-set metot, Düzlemsel anizotropi, Akma yüzeyleri

\section{Giriş}

Sac malzemeler, haddeleme prosesi sonrasinda meydana gelen tercihli yönlenme nedeniyle mekanik özelliklerinde anizotropi sergilemektedirler [1]. Plastik anizotropi, Lankford katsayısı (r değeri) olarak belirtilen bir parametre ile ifade edilmektedir ve çekme testinde \%15'lik bir mühendislik gerinim değerinde numunenin genişlik yönündeki plastik gerinimlerinin, kalınlık yönündeki plastik gerinimlerine oranı ile belirlenmektedir. Bu parametre, sacin incelmeye karşı direncini göstermektedir ve proses sırasında malzeme akışı, sınır gerinim değerleri üzerinde önemli bir etkisi bulunmaktadır. $\mathrm{Bu}$ nedenle, sonlu eleman analizlerinden gerçekçi sonuçlar elde edebilmek için malzeme anizotropisinin doğru bir şekilde tanımlanabilmesi gerekmektedir. Sonlu eleman analizlerinde sac malzemenin plastik davranışı ve anizotropisi düzlem gerilmeli ortotropik akma kriterleriyle tanımlanmaktadır. Literatürde ilk anizotropik akma kriteri 1948 yılında Hill tarafından önerilmiştir [2]. Hill48 akma kriteri, düzlem gerilme hali için
Abstract

In this study, performances of sequential quadratic programming and active-set methods from numerical optimization techniques were investigated in the determination of Yld2000 yield function coefficients. Two aluminum alloys (AA6111-T4, AA6181-T4) and a high strength steel sheet material (DP980) were selected in the study. Methods were examined according to their convergence rate and the number of function evaluations that occurred during the minimization and it was determined that active-set method was more successful than sequential quadratic programming for three materials. The variations of the yield stress ratios and Lankford coefficients in the sheet plane and positive regions of yield surfaces of the materials were predicted and theoretical results were compared with experimental results to validate the method. It is seen from the comparisons that planar anisotropy and yield surfaces of the materials in the positive regions could be successfully predicted.

Keywords: Yld2000, Sequential quadratic programming, Active-set method, Planar anisotropy, Yield surfaces

4 katsayıya sahiptir ve bu katsayılar analitik olarak kolayca belirlenebilmektedir. Ancak, kriter yüksek anizotropiye sahip Al alaşımları, Ti alaşımları ve yüksek mukavemetli çelikler için doğru sonuçlar verememektedir. 2000 yılından itibaren bu malzemelerin anizotropik davranışlarının modellenebilmesi için yüksek sayıda katsayıya sahip gelişmiş akma kriterleri önerilmektedir [3]. Bu akma kriterlerine ait parametreler, nonlineer denklem sistemi oluşturmaktadır ve belirlenebilmeleri için çeşitli nümerik yöntemlerin uygulanması gerekmektedir [4]. Literatürde farklı akma kriterleri üzerinde farklı nümerik metotların uygulandığı ve başarılı sonuçların elde edilmiş olduğu çok sayıda çalışma bulunmaktadır.

Barlat vd. [5] AA 2090-T3 ve AA 6022-T4 alüminyum alaşımları için Yld2000 akma kriteri parametrelerinin belirlenmesinde Newton-Raphson (N-R) metodunu uygulamışlar ve malzemelerin anizotropik davranışlarını modelleyebilmişlerdir. Cazacu ve Barlat [6] 2001 yılında geliştirmiş oldukları Cazacu-Barlat (CB2001) akma kriterini

\footnotetext{
* Sorumlu yazar / Corresponding author, e-posta / e-mail: borasen@ yildiz.edu.tr (B. Şener)

Geliș / Recieved: 16.11.2020 Kabul / Accepted: 15.02.2021 Yayımlanma / Published: 27.07.2021

doi: 10.28948 /ngumuh. 826850
} 
AA 2026-T3511 ve AA 6022-T4 aluminyum alaşımlarının modellenmesine uygulamışlar ve malzemelere ait model parametrelerini N-R metodu ile belirlemişlerdir. Benzer bir çalışma, Aretz vd. tarafından [7] Yld2003 kriteri için gerçekleştirilmiş ve N-R metodu ile araştırmacılar düşük karbonlu çelik, AA2090-T3 ve 5000 serisi aluminyum alaşımlarının düzlemsel anizotropilerini tanımlayabilmişlerdir. Yukarıda belirtilen çalışmalarda araştırmacılar N-R metodu ile başarılı sonuçlar elde edebilmişlerdir. Ancak N-R metodu ile nonlineer denklem sisteminin çözümünde her zaman çözüm elde edilememektedir. Metot, çözüme ulaşmak için her seferinde non-lineer denklem sisteminin Jacobienini hesaplamakta ve bunun tersini alarak değişkenlerin değerlerini belirlemektedir. $\mathrm{Bu}$ işlem, belli bir yakınsama sağlanıncaya kadar devam etmektedir. Bu nedenle metotun çözümü uzun sürmekte ve uygulaması pratik olmamaktadır. Ayrıca, bazı durumlarda sistemin Jacobieni tekil olmakta ve tersi alınamadığı için çözüm elde edilememektedir. Bununla birlikte metot, değişkenler için seçilen ilk değerlere bağlidır ve eğer kökten uzak değerler seçilmişse N-R metodu global minimuma yakınsayamamaktadır [8]. N-R metodunun bu gibi dezavantajlı durumları nedeniyle, hata fonksiyonunun minimizasyonu alternatif bir tanımlama yöntemi olarak geliştirilmiş ve çalışmalarda kullanılmıştır. Banabic vd. [9], 2000 yılında geliştirmiş oldukları Banabic-Balan-Comsa (BBC2000) modeline ait parametreleri belirlemek için inişli simpleks algoritmasını kullanmışlar ve 6000 serisi aluminyum alaşımlarının anizotropik davranışlarını modellemişlerdir. Aretz [10], Yld2003 malzeme modeli parametreleri için hata fonksiyonunu en dik iniş optimizasyon yöntemi ile minimize etmiş ve AA2090-T3 ve AA6111-T4 aluminyum alaşımları için model parametrelerini belirlemiştir. Comsa ve Banabic [11] AA2090-T3 aluminyum alaşımının anizotropik davranışını BBC2008 akma kriteri ile tanımlamışlar ve LevenbergMarquardt algoritmas1 ile hata fonksiyonunu minimize ederek model parametrelerini tespit etmişlerdir. Hata fonksiyonunun minimizasyonunda türev içeren metotlardan farklı olarak sezgisel algoritmalar da literatürde yaygın bir şekilde kullanılmaktadır. Bu metotların içerisinde genetik algoritma çoğu araştırmacı tarafindan optimizasyon problemlerinin çözümünde tercih edilmektedir. Kohar vd. [12] AA6063 alüminyum alaşımının plastik davranışını Yld2004 malzeme modeline göre modellemişler ve genetik algoritma ile hata fonksiyonunu minimize ederek model parametrelerini tespit etmişlerdir. Abedini vd. [13] AA2090T3 ve AA7075-T6 için yaptıkları çalışmada, genetik algoritma ile Yld2000 malzeme modelinin katsayılarını kalibre etmişlerdir. K1lıç vd. [14] genetik algoritma, en küçük kareler ve kısıtlı optimizasyon yöntemlerini kullanarak Yld2000 kriterinin katsayılarını AA7003-T6 ve AA6063-T6 alüminyum alaşımları için belirlemişler ve ayrıca yöntemlerin ilk değere olan bağlılıklarını da incelemişlerdir.

$\mathrm{Bu}$ çalışmada, Yld2000 malzeme modelinin parametrelerinin tanımlanmasında nümerik optimizasyon metotlarından ardışık kuadratik programlama ve aktif set metotlarının performansları karşılaştırılmıştır. Karşılaştırma
AA6111-T4, AA6181-T4 alüminyum alaşımları ve DP980 çift fazlı çelik için gerçekleştirilmiştir. Karşılaştırmada metotların yakınsaması ve minimizasyon sırasında değerlendirdikleri fonksiyon sayısı dikkate alınmıştır. Performans değerlendirmesinin ardından, malzemeler için belirlenmiş olan Yld2000 katsayılarıyla malzemelerin düzlemsel anizotropileri ve akma yüzeylerinin pozitif bölgeleri tahmin edilmiş ve deneysel sonuçlarla karşılaştırılmıştır.

Çalışma 4 bölümden oluşmakta olup, 2. Bölümde Yld2000 malzeme modeli, ardışık kuadratik programlama ve aktif set metotları hakkında bilgi verilmiş, 3 . Bölümde her iki optimizasyon metodu malzemelere uygulanmıs, metotlar karşılaş̧ırılmış ve her iki metoda göre belirlenmiş Yld2000 katsayıları kullanılarak, malzemelerin akma gerilmesi oranlarının ve Lankford katsayılarının sac düzlemi içerisindeki değişimleri tahmin edilmiş ve teorik sonuçlar deneysel sonuçlarla karşılaştırılmıştır. Çalışmanın son bölümünde ise elde edilen sonuçlar yorumlanmış ve malzemeler için en uygun yöntem belirlenmiştir.

\section{Materyal ve metot}

$\mathrm{Bu}$ çalışmada, otomotiv endüstrisinde kullanılan AA6111-T4, AA6181-T4 alüminyum alaşımları ve DP980 çift fazlı çelik test malzemesi olarak seçilmiştir. Belirtilen malzemelerin anizotropik davranışlarının tanımlanmasında Yld2000 malzeme modeli kullanılmıştır. Aşağıda YLD2000 akma fonksiyonu ve çalışma kapsamında uygulanan ardışık kuadratik ve aktif-set nümerik optimizasyon yöntemleri anlatılmaktadır.

\subsection{Yld2000 akma fonksiyonu}

Yld2000 kriteri, lineer dönüşüm yaklaşımına dayalı olarak geliştirilmiş bir anizotropik akma fonksiyonudur ve Denklem (1)' de ifade edilmektedir.

$$
\left|\tilde{S}_{1}^{\prime}-\tilde{S}_{2}^{\prime}\right|^{a}+\left|2 \tilde{S}_{2}^{\prime \prime}+\tilde{S}_{1}^{\prime \prime}\right|^{a}+\left|2 \tilde{S}_{1}^{\prime \prime}+\tilde{S}_{2}^{\prime \prime}\right|^{a}=2 \bar{\sigma}^{a}
$$

Eşdeğer olarak akma fonksiyonu efektif gerilme cinsinden aşağıdaki gibi yazılır.

$\bar{\sigma}=\left\{\frac{1}{2}\left(\left|\tilde{S}_{1}^{\prime}-\tilde{S}_{2}^{\prime}\right|^{a}+\left|2 \tilde{S}_{2}^{\prime \prime}+\tilde{S}_{1}^{\prime \prime}\right|^{a}+\left|2 \tilde{S}_{1}^{\prime \prime}+\tilde{S}_{2}^{\prime \prime}\right|^{a}\right)\right\}^{1 / a}$

$\mathrm{Bu}$ eşitliklerde, $\tilde{S}_{1}^{\prime}, \tilde{S}_{2}^{\prime}$ ve $\tilde{S}_{1}^{\prime \prime}, \tilde{S}_{2}^{\prime \prime}$ dönüşüme uğramış deviatörik tensörlerin $\left(\tilde{s}^{\prime}\right.$ ve $\left.\tilde{s}^{\prime \prime}\right)$ asal değerlerini, $a$ ise malzemenin kafes türünü belirten bir üsteli ifade etmekte olup, hacim merkezli kafes yapısına sahip malzemeler için 6 , yüzey merkezli kafes yapısına sahip malzemeler için ise 8 alınmaktadır.

Dönüşüme uğramış deviatörik tensörler, düzlem gerilme hali ve ortotropik simetri gözönünde bulundurularak aşağıdaki gibi matris formunda yazılabilirler:

$$
\tilde{s}^{\prime}=\left[\begin{array}{c}
\tilde{s}_{x x}^{\prime} \\
\tilde{s}_{y y}^{\prime} \\
\tilde{s}_{x y}^{\prime}
\end{array}\right]=\left[\begin{array}{ccc}
\alpha_{1} & 0 & 0 \\
0 & \alpha_{2} & 0 \\
0 & 0 & \alpha_{7}
\end{array}\right]\left[\begin{array}{l}
s_{x x} \\
s_{y y} \\
s_{x y}
\end{array}\right]
$$




$$
\tilde{s}^{\prime \prime}=\left[\begin{array}{c}
\tilde{s}_{x x}^{\prime \prime} \\
\tilde{s}_{y y}^{\prime \prime} \\
\tilde{s}_{x y}^{\prime \prime}
\end{array}\right]=\left[\begin{array}{ccc}
\frac{4 \alpha_{5}-\alpha_{3}}{3} & \frac{2 \alpha_{6}-2 \alpha_{4}}{3} & 0 \\
\frac{2 \alpha_{3}-2 \alpha_{5}}{3} & \frac{4 \alpha_{4}-\alpha_{6}}{3} & 0 \\
0 & 0 & \alpha_{8}
\end{array}\right]\left[\begin{array}{c}
s_{x x} \\
s_{y y} \\
s_{x y}
\end{array}\right]
$$

Düzlem gerilme hali için asal değerler yazılırsa, Denklem (1) deki üç mutlak değer içerisindeki ifadeler aşağıdaki gibi belirlenirler.

$$
\begin{gathered}
\left|\tilde{S}_{1}^{\prime}-\tilde{S}_{2}^{\prime}\right|=2 \sqrt{\left(\frac{\left.\tilde{s}_{x x}^{\prime}-\tilde{s}_{y y}^{\prime}\right)^{2}+\tilde{s}_{x y}^{\prime}{ }^{2}}{2}\right.} \\
\left|2 \tilde{S}_{2}^{\prime \prime}+\tilde{S}_{1}^{\prime \prime}\right|=\frac{3}{2}\left(\tilde{s}_{x x}^{\prime \prime}+\tilde{s}_{y y}^{\prime \prime}\right)-\sqrt{\left(\frac{\tilde{s}_{x x}^{\prime}-\tilde{s}_{y y}^{\prime}}{2}\right)^{2}+\tilde{s}_{x y}^{\prime}{ }^{2}}
\end{gathered}
$$

Denklem (3) ve Denklem (4) deki ifadeler Denklem (5)'de yerine yazılırsa, akma fonksiyonunda bulunan mutlak değer içerisindeki ifadeler deviatörik gerilme bileşenlerine ve buradan da gerilme bileşenlerine bağlı olarak ifade edilmiş olurlar.

Yukarıdaki ifadelerde görüldüğü gibi Yld2000 akma fonksiyonunun tanımlanabilmesi için 8 katsayının belirlenmesi gereklidir. Bu katsayılardan altısı malzemenin haddeleme yönüne paralel, diyagonal ve dik yönlerindeki akma gerilmeleri $\left(\sigma_{0}, \sigma_{45}, \sigma_{90}\right)$ ve Lankford katsayıları $\left(r_{0}, r_{45}, r_{90}\right)$ ile belirlenmekte olup, ilgili mekanik özellikler tek eksenli çekme testleriyle tespit edilmektedir. Geriye kalan iki katsayı malzemenin iki eksenli akma gerilmesi $\left(\sigma_{b}\right)$ ve Lankford katsayısı $\left(\mathrm{r}_{\mathrm{b}}\right)$ ile belirlenmektedir. $\mathrm{Bu}$ parametreler ise sırasıyla şişirme ve disk basma testleri ile tespit edilmektedir $[5,15]$. Bu çalışmada, Yld2000 akma fonksiyonunun katsayılarının belirlenmesinde hata minimizasyon prosedürü uygulanmıştır. $\mathrm{Bu}$ yönteme göre, akma kriterinden tahmin edilen akma gerilmeleri ve Lankford katsayıları ile deneysel sonuçlar arasındaki farkların kareleri toplamından oluşan bir hata fonksiyonu tanımlanmıştır:

$$
\begin{aligned}
E\left(\alpha_{i}\right)=\sum_{j=1}^{3} w_{1}\left(\frac{\sigma_{\theta j}}{\sigma_{d j}}-1\right)^{2}+w_{2}\left(\frac{\sigma_{b}}{\sigma_{b d}}-1\right)^{2} & \\
& +\sum_{k=1}^{3} w_{3}\left(\frac{r_{\theta k}}{r_{d k}}-1\right)^{2}+w_{4}\left(\frac{r_{b}}{r_{b d}}-1\right)^{2}
\end{aligned}
$$

$\mathrm{Bu}$ ifadede, $\sigma_{\theta}$ ve $r_{\theta}$ sirasiyla hadde yönüne göre $\theta$ açısında tahmin edilen akma gerilmesini ve Lankford katsayısını, $\sigma_{d}$ ve $r_{d}$ parametrelerin deneysel değerlerini, $\sigma_{b}$ ve $r_{b}$ ise iki eksenli akma gerilmesi ve Lankford katsayısını ifade etmektedir. Her iki parametre de akma fonksiyonu ve akış kuralına göre kriterden tahmin edilmektedir. Eşitlikteki $w$ katsayıları ise ağırlık katsayıları olup, bu çalışmada 1 alınmıştır. Çalışmada hata fonksiyonu minimize edilerek ilgili malzemeler için Yld2000 kriterinin katsayıları belirlenmiştir. Minimizasyonda nümerik optimizasyon metotlarından ardışık kuadratik programlama ve aktif set metotları uygulanmıştır. Belirtilen metotlar alt bölüm 2.2'de açıklanmaktadır.

\subsection{Ardışık kuadratik programlama}

Ardışık kuadratik programlama metodu, arama yönünün belirlenmesi ve ardından belirlenen yön boyunca adım uzunluğunun hesaplanması olmak üzere iki aşamadan oluşmaktadır. Metot, arama yönünü belirleyebilmek için her iterasyonda bir kuadratik programlama altproblemini çözmektedir. Metotta, öncelikle Lagrange fonksiyonu aracılığıyla kuadratik programlama altproblemi formüle edilmektedir. Altproblem aşağıdaki gibi tanımlanmaktadır:

$$
\begin{gathered}
\min \bar{f}=\frac{1}{2} d^{T} H_{k} d+\nabla f\left(x_{k}\right)^{T} d \\
\nabla g_{i}\left(x_{k}\right)^{T} \mathrm{~d}+g_{i}\left(x_{k}\right)=0, i=1, \ldots \ldots, m \\
\nabla g_{i}\left(x_{k}\right)^{T} \mathrm{~d}+g_{i}\left(x_{k}\right) \leq 0, i=1, \ldots \ldots, m
\end{gathered}
$$

Burada Lagrange fonksiyonunun kritik noktaları Newton metodu ile belirlenmekte ve istenilen yakınsama sağlanıncaya kadar kuadratik altproblemlerin çözümüne devam edilmektedir.

\subsection{Aktif set metodu}

Aktif set metodu kuadratik programlama problemlerinin çözümünde kullanılan yaklaşımlardan birisidir. Metotta ilk olarak optimum aktif setin $(A)$ tahmini ile başlanır. Mevcut aktif set kümesinden bir indeks çıkarmak için türev ve Lagrange çoğaltıcıları kullanılır. Bir sonraki nokta aşağıdaki eşitliğe göre belirlenir:

$$
x_{k+1}=x_{k}+\alpha_{k} d_{k}
$$

Burada $\alpha_{k}$ adım uzunluğunu ve $d_{k}$ ise kuadratik programlama altprobleminin çözümünden elde edilen arama yönünü göstermektedir. Bu altproblem, çalışma seti olarak adlandırılan $\left(W_{k}\right)$ ve eşitlik olarak dayatılmış olan kısıtlamaların bir alt kümesine sahiptir. Metotta, KarushKuhn-Tucker (KKT) koşullarına göre tüm Lagrange çoğaltıcıları pozitif olana ya da optimum koşullar sağlanana kadar yeni değerler hesaplanmakta ve çalışma seti güncellenmektedir. Optimizasyon problemi aşağıdaki gibi formule edilir:

$$
\min _{d_{k}} f\left(d_{k}\right)=\frac{1}{2} d_{k}^{T} Q d_{k}+g_{k}^{T} d_{k}
$$

s.to:

$$
a_{i}^{T}\left(x_{k}\right)=b_{i}, i \in W_{k}
$$

Çalıșma setinde tüm $i$ indisleri için $a_{i}{ }^{T}$ içeren matris $A$ ile ifade edilirse;

$$
A=\left[a_{i}^{T}\right], i \in W_{k}
$$

Lagrange fonksiyonu aşağıdaki gibi yazılır:

$$
L\left(d_{k}, \lambda\right)=\frac{1}{2} d_{k}{ }^{T} Q d_{k}+g_{k}{ }^{T} d_{k}+\lambda^{T} A d_{k}
$$


KKT birinci-derece optimallik koşuluna göre;

$$
\begin{gathered}
\frac{\partial L}{\partial d_{k}}=Q d_{k}+g_{k}+A^{T} \lambda=0 \\
A d_{k}=0
\end{gathered}
$$

$\mathrm{Bu}$ ifade matris formunda aşağıdaki gibi yazılır:

$$
\left[\begin{array}{cc}
Q & A^{T} \\
A & 0
\end{array}\right]\left[\begin{array}{c}
d_{k} \\
\lambda
\end{array}\right]=\left[\begin{array}{c}
-g_{k} \\
0
\end{array}\right]
$$

Lineer denklem sisteminin çözümü ile yön $d_{k}$ ve Lagrange çoğaltıcıları belirlenir [16].

\section{Bulgular ve tartışma}

$\mathrm{Bu}$ bölümde, yukarıda anlatılan nümerik optimizasyon yöntemleri hata fonksiyonunun minimizasyonunda uygulanmış ve AA6111-T4 $(\mathrm{t}=1 \mathrm{~mm})$, AA6181-T4 $(\mathrm{t}=1.13$ $\mathrm{mm})$ ve DP980 $(\mathrm{t}=1.2 \mathrm{~mm})$ malzemeleri için Yld2000 akma fonksiyonunun katsayıları belirlenmiştir. Malzemelerin mekanik özellikleri literatürden alınmış olup, sırasıyla Tablo 1, Tablo 2 ve Tablo 3'de sunulmuştur.

Tablo 1. AA6111-T4 alaşımının mekanik özellikleri [17]

\begin{tabular}{cccccccc}
\hline$\sigma_{0}$ & $\sigma_{15}$ & $\sigma_{30}$ & $\sigma_{45}$ & $\sigma_{60}$ & $\sigma_{75}$ & $\sigma_{90}$ & $\sigma_{b}$ \\
\hline 194.1 & 189.6 & 182.2 & 177.9 & 176.5 & 175.0 & 173.4 & 184.2 \\
$r_{0}$ & $r_{15}$ & $r_{30}$ & $r_{45}$ & $r_{60}$ & $r_{75}$ & $r_{90}$ & $r_{b}$ \\
0.894 & 0.885 & 0.743 & 0.611 & 0.611 & 0.627 & 0.660 & 1.225 \\
\hline
\end{tabular}

Tablo 2. AA6181-T4 alaşımının mekanik özellikleri [18]

\begin{tabular}{cccccccc}
\hline$\sigma_{0}$ & $\sigma_{45}$ & $\sigma_{90}$ & $\sigma_{b}$ & $r_{0}$ & $r_{45}$ & $r_{90}$ & $r_{b}$ \\
\hline 142 & 138 & 137 & 134 & 0.672 & 0.606 & 0.821 & 0.820 \\
\hline
\end{tabular}

Tablo 3. DP980 malzemenin mekanik özellikleri [19]

\begin{tabular}{cccccccc}
\hline$\sigma_{0}$ & $\sigma_{15}$ & $\sigma_{30}$ & $\sigma_{45}$ & $\sigma_{60}$ & $\sigma_{75}$ & $\sigma_{90}$ & $\sigma_{b}$ \\
\hline 684.2 & 676.9 & 669.9 & 676.6 & 685.2 & 691.4 & 701.5 & 691.04 \\
$r_{0}$ & $r_{15}$ & $r_{30}$ & $r_{45}$ & $r_{60}$ & $r_{75}$ & $r_{90}$ & $r_{b}$ \\
0.691 & 0.760 & 0.888 & 1.050 & 1.080 & 1.020 & 0.959 & 0.879 \\
\hline
\end{tabular}

Çalışmada ilk olarak iki yöntemin performansları değerlendirilmiştir. Değerlendirme sonuçları gözönünde bulundurulmuş ve ardından her iki metoda göre Yld2000 akma kriterinden tahmin edilen sonuçlar doğrulama için deneysel sonuçlarla karşılaştırılmıştır.

\subsection{Yöntemlerin performanslarının değerlendirilmesi}

Ardış1k kuadratik ve aktif set optimizasyon yöntemlerinin değerlendirilmesinde, yöntemlerin minimizasyon sırasında yakınsamaları ve değerlendikleri fonksiyon sayıları dikkate alınmıştır. Test edilen üç malzeme için elde edilen sonuçlar sırasıyla Şekil 1, 2 ve 3'de gösterilmektedir.
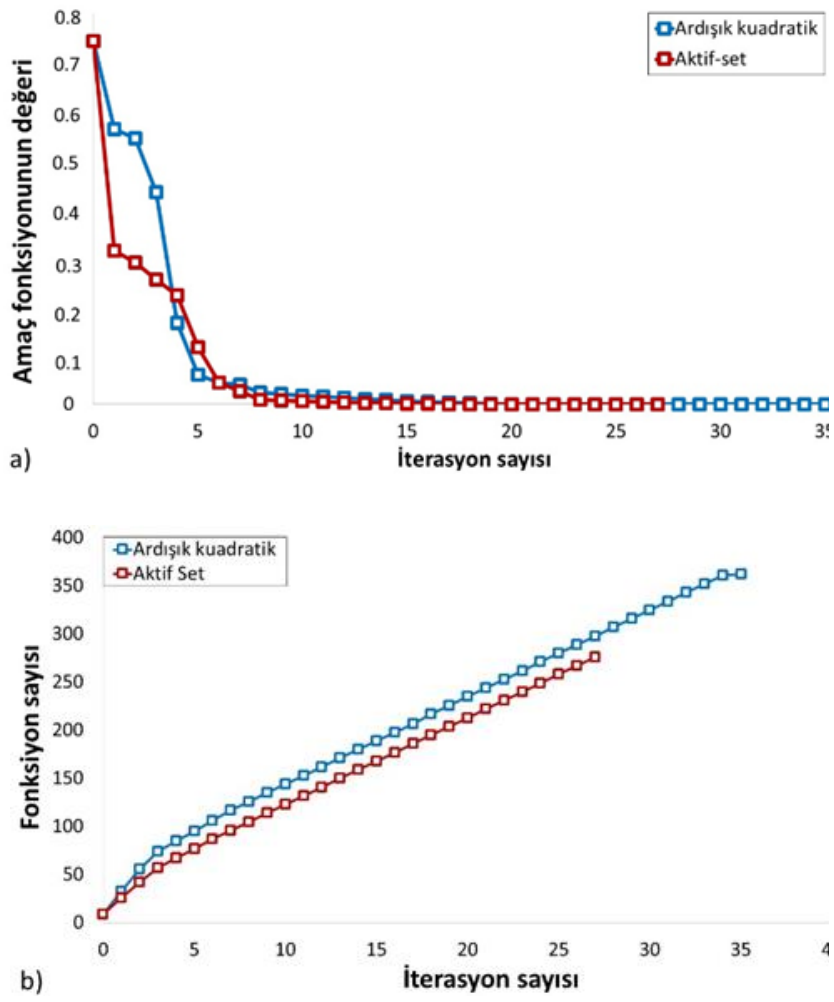

Şekil 1. AA6111-T4 alaşımı için yöntemlerin karşılaştırılması a) amaç fonksiyonunun değişimi, b) değerlendirilen fonksiyon sayısı
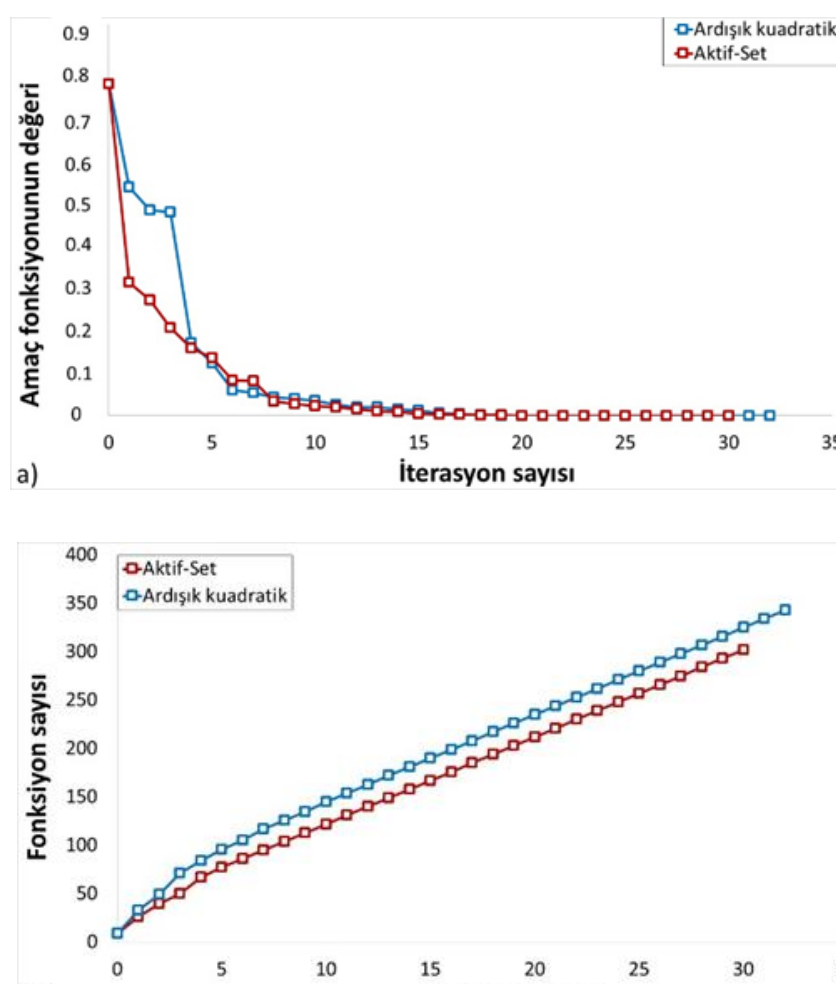

b)

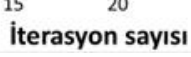

Şekil 2. AA6181-T4 alaşımı için yöntemlerin karşılaştırılması a) amaç fonksiyonunun değişimi, b) değerlendirilen fonksiyon sayısı 

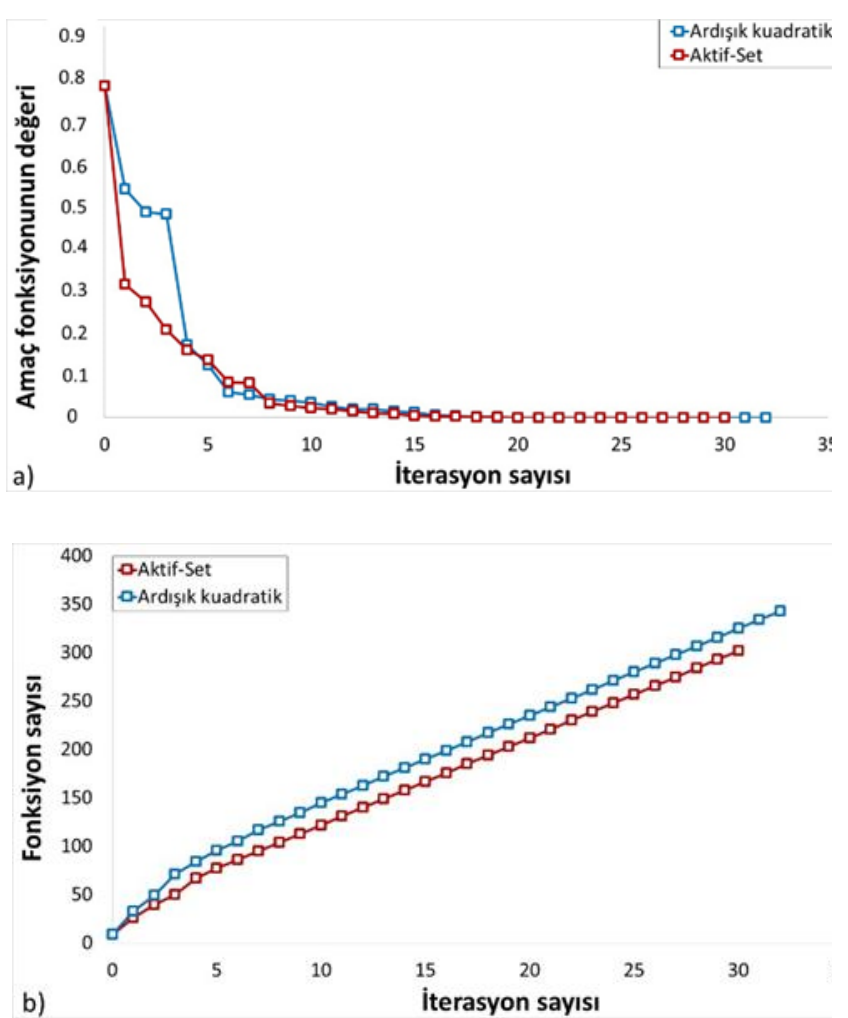

Şekil 3. DP980 için yöntemlerin karşılaștırılması a) amaç fonksiyonunun değişimi, b) değerlendirilen fonksiyon sayıs1

Şekil 1, 2 ve 3'den görüldüğü gibi her iki yöntem de tüm malzemeler için global minimuma yakınsamıştır. Burada, aktif-set metodunun tüm test malzemelerinde daha az iterasyon sayısı ile yakınsayabildiği görülmektedir. Bu sonuç aktif set-metodunun ardışık kuadratik programlamaya göre daha hızlı bir yöntem olduğunu göstermektedir. Minimizasyon sırasında, değerlendirilen amaç fonksiyonu sayısına bakıldığında ise, aktif set metodunun üç malzeme için de aynı iterasyon sayısında ardışık kuadratik programlamaya göre daha az sayıda fonksiyon değerlendirdiği görülmektedir. Bu da metodun verimliliğini göstermektedir.

\subsection{Deneysel sonuçlarla karşılaştırma}

Metotların doğrulamasında, her iki optimizasyon yöntemi test edilen tüm malzemeler için uygulanmış ve malzemelerin Yld2000 katsayıları belirlenmiştir. Ardından malzemelerin akma gerilmesi oranı, Lankford katsayılarının hadde yönüne göre değişimleri ile akma yüzeylerinin pozitif bölgeleri tahmin edilmiş ve teorik sonuçlar deney sonuçlarıyla karşılaştırılmıştır. Çalışmada, aynı malzeme için her iki yöntemden elde edilen model parametrelerinin aynı olduğu görülmüş olup, malzemeler için belirlenmiş katsayılar ve karşılaştırma sonuçları aşağıda sunulmuştur.

Tablo 4. AA6111-T4 alaşımının Yld2000 katsayıları

\begin{tabular}{cccccccc}
\hline$\alpha_{1}$ & $\alpha_{2}$ & $\alpha_{3}$ & $\alpha_{4}$ & $\alpha_{5}$ & $\alpha_{6}$ & $\alpha_{7}$ & $\alpha_{8}$ \\
\hline 0.898 & 1.169 & 0.945 & 1.099 & 1.035 & 1.108 & 1.037 & 1.207 \\
\hline
\end{tabular}

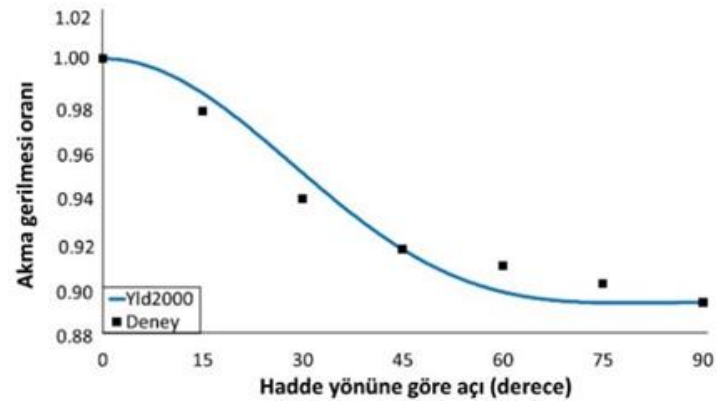

Şekil 4. Akma gerilmesi oranının açıya göre değişimi

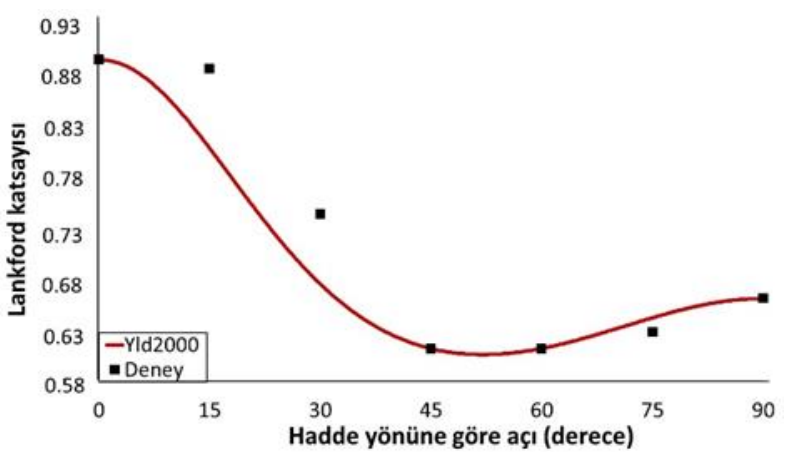

Şekil 5. Lankford katsayısının açıya göre değişimi

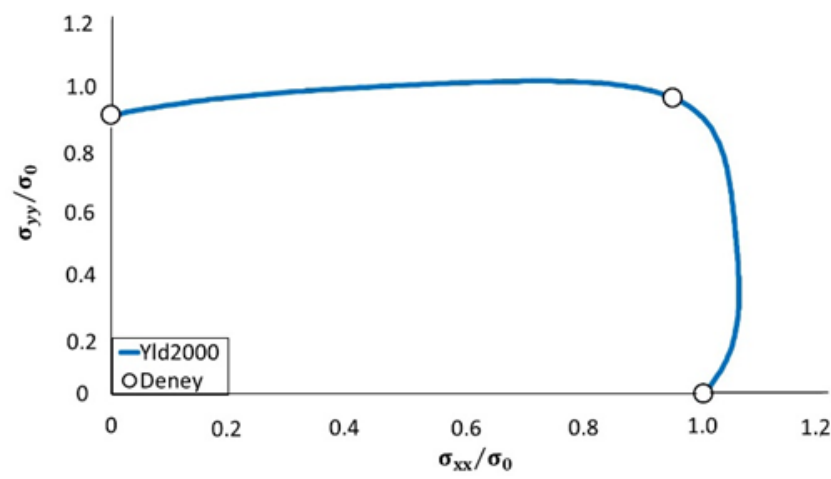

Şekil 6. Akma yüzeyinin pozitif bölgesi (AA6111-T4)

Tablo 5. AA6181-T4 alaşımının Yld2000 katsayıları

\begin{tabular}{cccccccc}
\hline$\alpha_{1}$ & $\alpha_{2}$ & $\alpha_{3}$ & $\alpha_{4}$ & $\alpha_{5}$ & $\alpha_{6}$ & $\alpha_{7}$ & $\alpha_{8}$ \\
\hline 0.926 & 1.080 & 1.025 & 1.039 & 1.050 & 1.142 & 0.993 & 1.056 \\
\hline
\end{tabular}

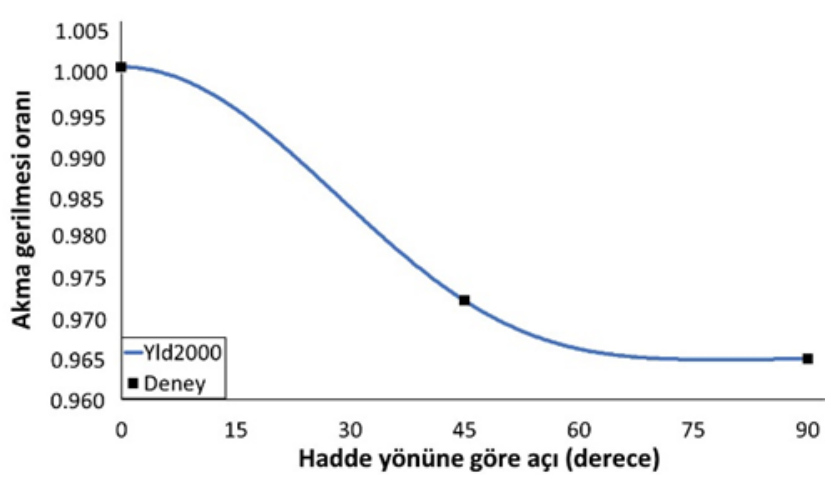

Şekil 7. Akma gerilmesi oranının açıya göre değişimi 


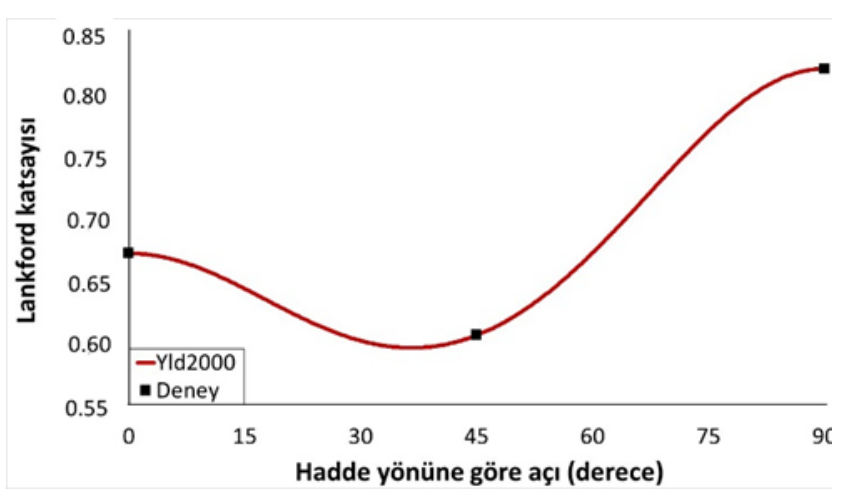

Şekil 8. Lankford katsayısının açıya göre değişimi

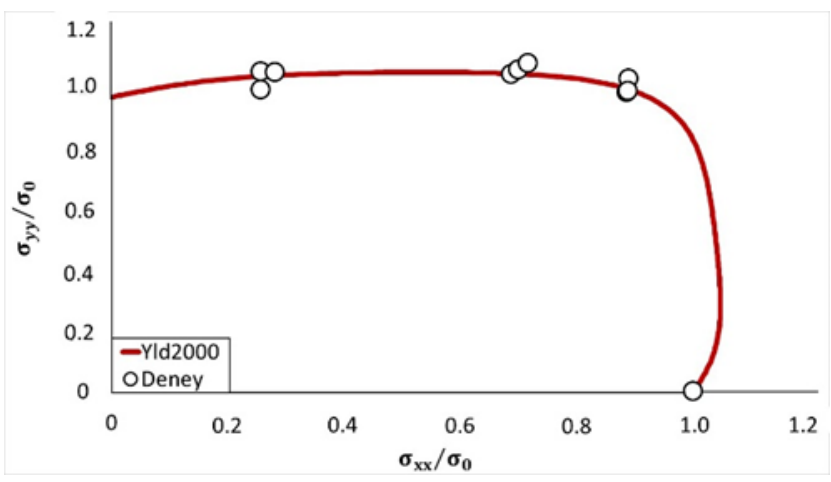

Şekil 9. Akma yüzeyinin pozitif bölgesi (AA6181-T4)

Tablo 6. DP980 malzemenin Yld2000 katsay1ları

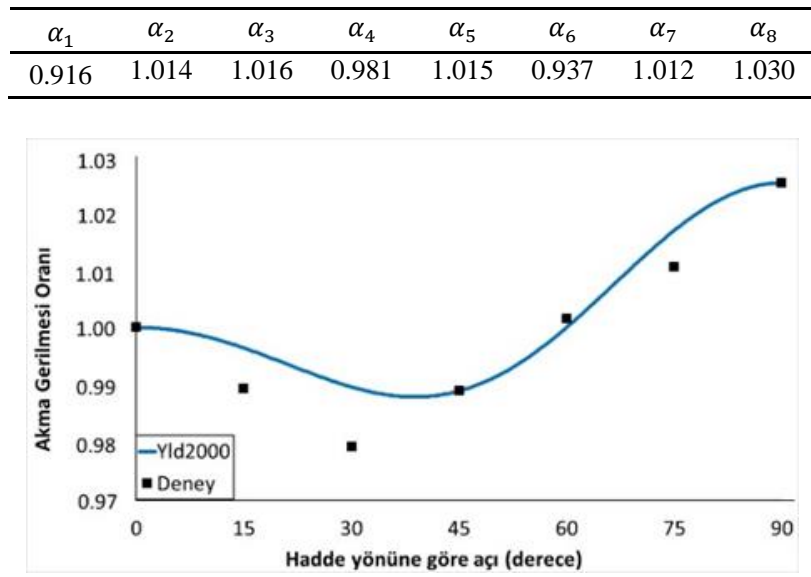

Şekil 10. Akma gerilmesi oranının açıya göre değişsimi

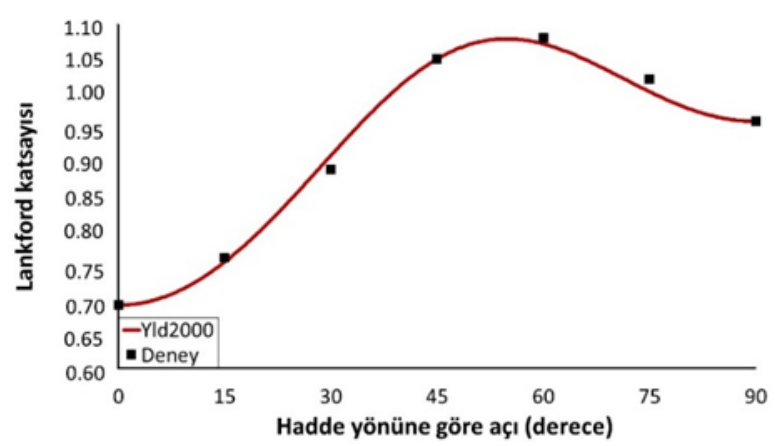

Şekil 11. Lankford katsayısının açıya göre değişimi

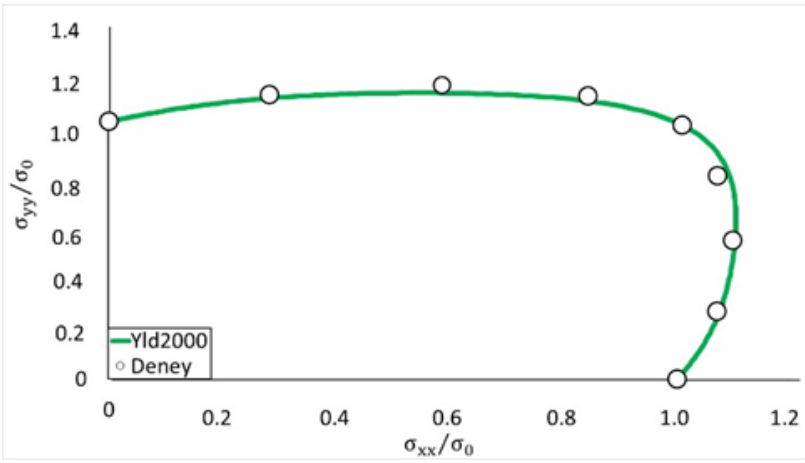

Şekil 12. Akma yüzeyinin pozitif bölgesi (DP980)

Şekil 4-12'de görüldüğü gibi Yld2000 kriteri ile üç malzemenin akma gerilmesi oranları, Lankford katsayıları ve akma yüzeylerinin pozitif bölgeleri başarılı bir şekilde tahmin edilmiştir. Çalışmada, malzemelerin akma gerilmesi oranlarının belirlenmesinde, haddeleme yönüne paralel yöndeki akma gerilmesi referans alınmış ve diğer yönlerdeki gerilmeler referans değere göre normalize edilmiştir. AA6181-T4 aluminyum alaşımı ve DP980 çift fazlı çeliğe ait farklı iki eksenli gerilme oranlarındaki deneysel değerler literatürden alınmıştır [18-19].

\section{Sonuçlar}

$\mathrm{Bu}$ çalışmada, Yld2000 malzeme modelinin katsayılarının belirlenmesinde nümerik optimizasyon yöntemlerinden ardışık kuadratik programlama ve aktif set metotları incelenmiş ve metotlar AA6111-T4, AA6181-T4 ve DP980 malzemeler üzerinde uygulanmıştır. Çalışmada elde edilen bulgulara dayanarak aşağıdaki sonuçlar çıkarılmıştır:

a) Yöntemler, minimizasyon sırasındaki yakınsama hızlarına ve değerlendirdikleri amaç fonksiyonu sayısına göre karşılaştırılmış olup, her iki durumda da üç malzeme için aktif-set metodunun ardışık kuadratik programlama metodundan daha başarılı olduğu görülmüştür.

b) Doğrulama amacıyla, ilk olarak her iki yönteme göre malzemelerin Yld2000 katsayıları belirlenmiştir. Belirlenen katsayılar incelendiğinde, aynı malzeme için her iki yöntemin aynı sonuçlar verdiği görülmüştür. Ardından malzemelerin akma gerilmesi oranı, Lankford katsayılarının sac düzlemi içerisindeki değişimleri tahmin edilmiş ve teorik sonuçlar deneysel sonuçlarla karşılaştırılmıştır. Yapılan karşılaştırmalarda, üç malzeme için tahmin edilen sonuçların deneysel sonuçlara oldukça yakın olduğu görülmüştür.

c) Gerilme oranı ve Lankford katsayıları ile birlikte malzemelerin akma yüzeylerinin pozitif bölgeleri de tahmin edilmiş ve farklı iki eksenli gerilme oranlarındaki deney sonuçlarıyla karşılaştırılmıştır. Yapılan karşılaştırmalarda üç malzemenin de akma yüzeylerinin pozitif bölgelerinin doğru bir şekilde tahmin edilebildiği görülmüştür.

d) Tüm bu sonuçlara göre, Yld2000 katsayılarının belirlenmesinde aktif-set metodunun kullanılması hız ve doğruluk açısından önerilmektedir. 


\section{Çıkar çatışması}

Yazar çıkar çatışması olmadığını beyan etmektedir.

\section{Benzerlik oranı (iThenticate): \%11}

\section{Kaynaklar}

[1] G. E. Dieter, Mechanical Metallurgy. McGraw-Hill Book Company, 1988.

[2] R. Hill, A theory of the yielding and plastic flow of anisotropic metals. Proceedings of the Royal Society of London Series A: Mathematical and Physical Sciences, 193 (A), 281-297, 1948. https://doi.org/10.1098/rspa. 1948.0045.

[3] D. Banabic, Sheet Metal Forming Processes Constitutive Modelling and Numerical Simulation. Springer, 2010

[4] K. Mattiasson and M. Sigvant, An evaluation of some recent yield criteria for industrial simulations of sheet forming processes. International Journal of Mechanical Sciences, 50, 774-787, 2008. https://doi.org/10.1016/ j.ijmecsci.2007.11.002.

[5] F. Barlat, J. C. Brem, J. W. Yoon, K. Chung, R. E. Dick, D. J. Lege, F. Pourboghrat, S. H. Choi, and E. Chu, Plane stress yield function for aluminum alloy sheetspart 1: theory. International Journal of Plasticity, 19, 1297-1319, 2003. https://doi.org/10.1016/S07496419(02)00019-0.

[6] O. Cazacu and F. Barlat, Application of the theory of representation to describe yielding of anisotropic aluminum alloys. International Journal of Engineering Science, 41, 1367-1385,2003. https://doi.org/10.1016/ S0020- 7225(03)00037-5.

[7] H. Aretz, O. S. Hopperstad, O-G. Lademo, Yield function calibration for orthotropic sheet metals based on uniaxial and plane strain tensile tests. Journal of Materials Processing Technology,186, 221-235, 2007. https://doi.org/10.1016/j.jmatprotec.2006.12.037.

[8] J. S. Arora, Introduction to Optimum Design. Elsevier, 2004.

[9] D. Banabic, T. Balan, D. S. Comsa, A new yield criterion for orthotropic sheet metals under plane-stress conditions. Proceedings of the 7th Conference, sayfa 217-224, Cluj Napoca, Romania, 11-12 May 2000.

[10] H. Aretz, A non-quadratic plane stress yield function for orthotropic sheet metals. Journal of Materials Processing Technology,168,1-9,2005. https://doi.org/ 10.1016/j. jmatprotec.2004.10.008
[11] D. S. Comsa and D. Banabic, Plane-stress yield criterion for highly-anisotropic sheet metals, Proceedings of the $7^{\text {th }}$ International Conference and Workshop on Numerical Simulation of 3D Sheet Metal Forming Processes, sayfa 43-48, Interlaken, Switzerland, 1-5 September 2008.

[12] C. P. Kohar, A. Brahme, J. Imbert, R. K. Mishra, and K. Inal, Effects of coupling anisotropic yield functions with the optimization process of extruded aluminum front rail geometries in crashworthiness. International Journal of Solids and Structures, 128, 174-198, 2017. https://doi.org/10.1016/j.ijsolstr.2017.08.026.

[13] A. Abedini, C. Butcher, T. Rahmaan, and M. J. Worswick, Evaluation and calibration of anisotropic yield criteria in shear loading: constraints to eliminate numerical artefacts. International Journal of Solids and Structures, 151, 118-134, 2018. https://doi.org/ 10.1016/j. ijsolstr.2017.06.029.

[14] S. K1lıç, İ. Kaçar, F. Öztürk, and S. Toros, Effects of different optimization methods on the predictions of Yld2000 yield criterion coefficients. Niğde Ömer Halisdemir Üniversitesi Mühendislik Bilimleri Dergisi 8, 447-463, 2019. https://doi.org/10.28948/ngumuh. 517160.

[15] L. Lăzărescu, I. Nicodim, I. Ciobanu, D. S. Comşa, and D. Banabic, Determination of material parameters of sheet metals using the hydraulic bulge test. Acta Metallurgica Slovaca, 19, 4-12, 2013. https://dx.doi.org/10. 12776/ams.v19i1.81.

[16] Matlab Optimization Toolbox User' Guide. The MathWorks, Inc. 2016.

[17] J. C. Brem and F. Barlat, Characterization of aluminum alloy (6111-T4). 5th International Conference and Numerical Simulation of 3D Sheet Metal Forming Processes, Jeju Island, Korea, 21-25 October 2002.

[18] D. Banabic, H. Aretz, D. S. Comsa, and L. Paraianu, An improved analytical description of orthotropy in metallic sheets. International Journal of Plasticity, 21, 493-512, 2005. https://doi.org/10.1016/j.ijplas.2004. 04.003.

[19] T. Kuwabara, Hole expansion of high strength steel sheet. 11th International Conference and Workshop on Numerical Simulation of 3D Sheet Metal Forming Processes, Tokyo, Japan, 30 July-3 August 2018 